\title{
Contents, Vol. 104, 1965
}

\section{INDEX}

Bacci, G.: vide Cavalli, G.

Bansi, H. W.: Allgemeine Gesichtspunkte und die KH-Verwertung parenteral

Bianchi, F. B.: vide Cavalli, G.

Birke, G.: $\quad$ Untersuchungen über den normalen Albuminumsatz und die Albuminsynthese $\quad 69$

Booth, C. C.: Therapie des Malabsorptionssyndromes nach Dünndarmresektion .... 49

Bünte, H.: Die enterale und parenterale Resorption aus der Sicht des Chirurgen .. 92

Cavalli, G.; Orlandi, F.; Bianchi, F. B. and Bacci, G.:

Desoxyribonucleic Acid (DNA) of the Epithelium of the Small Intestine

in Organogenesis and in Portal Hypertension. An Experimental Study 197

Demling, L.: Physiologie, Pathophysiologie und klinische Aspekte der Kohlen-

hydratresorption 25

Dvorácek, C.: vide Rapant, V.

Felber, J.-P.: vide Robinson, J. W. L.

Grabowski, T.: The Effect of Magnesium Sulphate on the Radiological Behaviour of the Duodenal Bulb 261

Hauftová, D.: vide Procházka, J.

Henning, N.: Symptomatische Hämatologie bei Verdauungskrankheiten 165

Herbinger, W.: Mere und Mineralhaushalt 135

Herman, B. und Hermanová, K.:

Haemorrhagische Komplikationen des Verdauungstraktes bei Herz-

krankheiten 352

Hermanová, K.: vide Herman, B.

Hittmair, A.: Allgemeine symptomatische Hämatologie des Gastroenterons

Hoenig, V. et Hoenigová, J.:

Hémagglutination passive des érythrocytes tannés par le serum

d'hépatites aiguës et chroniques $\quad 368$

Hoenigová, J.: vide Hoenig, V.

Holzer, H. Krebs und Stoffwechsel 8

Hradský, M.: vide Langr, F.

Kojecký, Z. and Matlocha, Z.:

Quantitative Differences of Intestinal Disaccharidase Activity Follow

ing the Resection of Stomach 343

Khentz, K.: Ergebnisse der Dickenmessung der Magencorpusschleimhaut nach saugbioptischer Gewebsentnahme 272

Lang, K.: $\quad$ Enterale und parenterale Resorption 19

Langr, F.; Parízek, J.; Hradský, M. und Vortel, V.: 
Die Aktivität der Esterase. der alkalischen Phosphatase und Aminopeptidase in der Magenschleimhaut bei einigen präkanzerösen $\mathrm{Zu}-$ stiinden 213

Majdrakow, G.: vide Taschew, T.

Manousos, 0. N. and Salem, S. N.:

Abnormal Motility of the Small Intestine in Ulcerative Colitis

Mark, R. E.: Eröffnungsansprache 3

Martini, G. A.: Das sogenannte hepatorenale Syndrom 117

Matlocha, Z.: vide Kojecký, Z.

Matjrer, W.: Das obstruktive Pankreasoedem nach akzidenteller Gangligatur. Mit-

teilung von 3 Beobachtungen nach Magensekretion wegen Ulcus.... 236

Nikolow, N.: vide Taschew, T.

Orlandi, F.: vide Cavalli, G.

Parízek, J.: vide Langr, F.

Procházka, J. and Hauftová, D.:

Changes of Some Clotting Factors in Hepatolenticular Degeneration

(Wilson's Disease) 325

Pbuzanski, W.: Evaluation of the Influence of Steroids on the Level of Serum Bilirubin

in Viral Hepatitis 225

Rapant, V.; Dvorácek, C.; Turek, K. and Valach, V.:

Familial Occurrence of the Zollinger-Ellison Syndrome Associated with

Diabetes 289

Riederer, J.: Ein Fall von primärer Lymphogranulomatose des Jejunums mit Dick-

darmfistel 302

Robinson, J. W. L. and Felbeb, J.-P.:

Compartments of the Uptake of Aminoacids by Intestinal Fragments

During in vitro Incubation 335

Salem, S. N.: vide Manousos, 0. N.

Schettler, G.: Aufnahme, Verteilung und Verwertung parenteraler Fettinfusionen

(Referat) 75

Schulten, H.: M. Biermer und Gastroenteron 192

Stoilow, J.: vide Taschew, T.

Taschew, T.; Majdrakow, G.; Nikolow, N. und Stoilow, J.:

Uber manche morphologische und funktionelle Veränderungen der

Magenschleimhaut bei Kranken mit Magen- und Zwölffingerdarm-

geschwür 359

Turek, K.; vide Rapant, V.

Valach, V.: vide Rapant, V.

Valtonen, E. J.: Shellac and Lipoid Bezoars and Other Concretions of the Stomach .... 309

Vortel, V.: vide Langr, F.

Vossschtjlte, K.: Symptomatische Hämatologie des Gastrointestinaltraktes vom Stand-

punkt des Chirargen 175

Wenger, R.: Die enterale Resorption der Fette 33

Zöllner, N.: Enterale Eiweißresorption 43

Zollinger, H. U.: Morphologie der Niere bei Stoffwechselstörungen 
Deutsche Gesellschaft für Verdauungs- und Stoffwechselkrankheiten,

XXII. Tagung in Wiesbaden, 9.-11. April 1964 1

EDITORIAL La cholestyramine, medicament du prurit des ictériques

SEITE DER THERAPIE - PAGE DE THÉRAPEUTIQUE 258, 380

KONGRESSKALENDER - COMING MEDICAL MEETINGS - TABLEAU DES

CONGRÈS 384

BUCHBESPRECHUNGEN - BOOK REVIEWS - LIVRES NOUVEAUX $\quad 259,321,382$

VARIA 260

Ohne ausdrückliche Genehmigung des Verlages ist es auch nicht gestattet, diese Zeitschrift oder Teile daraus auf photoraechanischem Wege (Photokopie, Mikrokopie) zu vervielfaltigen.

(C)

Copyright 1965 by S. KaГger AG, Basel

Printed in Switzerland by Buchdruckerei Werner \& Bischoff AG, Basel

Cliches: Aberegg-Steiner \& Cie, A.G, Bern, und Steiner \& Cie, AG, Basel 